\title{
Maternal betaine supplementation during gestation modifies hippocampal expression of GR and its regulatory miRNAs in neonatal piglets
}

\author{
Qinwei SUN ${ }^{1)}$, Xi LI ${ }^{1)}$, Yimin JIA ${ }^{1)}$, Shifeng PAN ${ }^{1)}$, Runsheng $\mathrm{LI}^{1)}$, Xiaojing YANG ${ }^{1)}$ and Ruqian $\mathrm{ZHAO}^{1,2) *}$ \\ 1) Key Laboratory of Animal Physiology \& Biochemistry, College of Veterinary Medicine, Nanjing Agricultural University, Nanjing \\ 210095, P. R. China \\ 2) Jiangsu Collaborative Innovation Center of Meat Production and Processing, Quality and Safety Control, Nanjing 210095, P. R. China
}

(Received 30 November 2015/Accepted 28 January 2016/Published online in J-STAGE 11 February 2016)

\begin{abstract}
Methyl donor nutrients are critical for embryonic development of brain. Hippocampus is the most susceptible brain region to various factors including prenatal supply of methyl donors. Glucocorticoid receptor (GR) expressed in hippocampus is involved in the regulation of energy homeostasis and stress sensitivity. Hippocampal GR expression is highly susceptible to epigenetic regulation, yet the effect of maternal methyl donor supplementation on epigenetic regulation of GR transcription in offspring hippocampus remains unclear. In this study, we fed sows with betaine $(3 \mathrm{~g} / \mathrm{kg}$ ) throughout the gestation and analyzed the hippocampal expression of GR mRNA and its variants, as well as the CpG methylation status of the promoter and the microRNAs predicted to target 3' UTR of porcine GR gene in neonatal piglets. Total GR mRNA $(P<0.01)$ and its variants GR 1-4 $(P<0.05)$ and 1-9,10 $(P<0.01)$, were significantly higher in the hippocampus of betaine-treated piglets, while the content of GR protein was not significantly changed. The CpGs located in the $-1650 \sim-1515$ segment of GR gene were hypermethylated $(P<0.05)$. The hippocampal expression of miR-130b $(P<0.05)$, miR-181a $(P<0.05)$ and miR-181d $(P<0.01)$ was significantly up-regulated. The targeting efficacy of miR-130b and miR-181d was validated in vitro using dual-luciferase reporter assay system. Our results demonstrate that maternal betaine supplementation during gestation enhances GR mRNA expression in offspring hippocampus, which involves alterations in miRNAs expression.

KEY WORDS: betaine, glucocorticoid receptor, hippocampus, methylation, miRNA
\end{abstract}

doi: 10.1292/jvms.15-0678; J. Vet. Med. Sci. 78(6): 921-928, 2016

Methyl donor nutrients are critical for the embryonic development of central nervous system, especially brain [38]. Hippocampus is considered to be the most susceptible brain region to various factors including prenatal supply of methyl donors. Glucocorticoid receptor (GR) in hippocampus plays an important role in glucocorticoid negative feedback and therefore acts as an important component of the "set-point" for hypothalamic-pituitary-adrenal axis activity [9] which is known to be involved in the regulation of energy homeostasis [27] and stress-coping characteristics [14], as well as mental health and disorders [24, 39].

The regulation of GR gene transcription is tissue-specific through selective promoter usage and alternative splicing $[13,30,33$, ]. Multiple GR mRNA variants have been described in rodents $[6,25]$ and humans [34]. In our previous study, seven alternative 5 '-untranslated exons, 1-4, 1-5, 1-6, $1-7,1-8,1-9,10$ and 1-11 variants, were identified in pigs [41]. Furthermore, the association between the expression of GR exon 1 variants and the usage of alternative promoter regions was determined in different porcine tissues [29]. The 5 '-sequence of GR gene consists of numerous $\mathrm{CpG}$ sites

*Correspondence to: Zhao, R., Key Laboratory of Animal Physiology \& Biochemistry, College of Veterinary Medicine, Nanjing Agricultural University, Nanjing 210095, P. R. China.

e-mail: zhao.ruqian@gmail.com

(C)2016 The Japanese Society of Veterinary Science

This is an open-access article distributed under the terms of the Creative Commons Attribution Non-Commercial No Derivatives (by-nc-nd) License $<$ http://creativecommons.org/licenses/by-nc-nd/4.0/>. and $\mathrm{CpG}$ islands which are subjected to the modulation of CpG methylation. Moreover, GR mRNA contains a long 3' UTR with sequences complementary to the seed regions of multiple miRNAs [33]. The role of miR-18, miR-124a and $\mathrm{miR}-130 \mathrm{~b}$ in the regulation of GR expression has been reported in humans [32] and rodents [35]. Moreover, numerous studies have shown that maternal influences, such as nutrition [22] and nursing [36], can affect GR expression through epigenetic mechanisms, such as $\mathrm{CpG}$ methylation [7] and microRNA-mediated gene regulation [33].

A number of methyl donors, such as folate acid [21], choline [12] and methionine [37], have been reported to regulate the methylation status of GR promoter region. Betaine, which contains three chemically reactive methyl groups, is an important component of the methionine cycle which is essential for the epigenetic gene regulation [1]. Betaine is authorized to use as a feed additive in animal husbandry to improve the growth performance and meat quality $[8,28]$. Previously, we found that maternal dietary supplementation of betaine modulated CpGs methylation of differentially methylated regions (DMR) of IGF-1 promoter in the hippocampus of newborn offspring piglets [20]. However, whether hipocampal GR expression and epigenetic regulation are affected by maternal betaine supplementation in neonatal piglets remains unknown.

In this study, betaine was supplemented to the diet of sows throughout the gestation, and hippocampi of the newborn piglets were collected to investigate the abundance of GR mRNA and its variants, as well as the $\mathrm{CpG}$ methylation status on GR promoter and the expression of miRNAs pre- 
dicted to target 3'UTR of porcine GR mRNA. The findings will help to understand the epigenetic regulation of porcine GR gene in hippocampus and may also shed light on our understanding of the central mechanism underlying the biological functions of betaine in pigs.

\section{MATERIALS AND METHODS}

Animal and treatment: One week after the artificial insemination, second parity Landrace $\times$ Yorkshire crossbred sows were randomly divided into two groups. Sows in control group $(n=6)$ were fed with standard diet (Table 1), and those in betaine group $(n=6)$ were fed with diet supplemented with $3 \mathrm{~g} /$ $\mathrm{kg}$ betaine hydrochloride of 98\% purity (Skystone Feed Co., Ltd., YiXing, China) throughout the whole pregancy stage. All animals were treated in the same way of insemination and reared under the same housing condition. The hippocami of male offspring (one per litter) were sampled at delivery, immediately frozen in liquid nitrogen and stored at $-80^{\circ} \mathrm{C}$.

Operating procedures for animal breeding and husbandry were in accordance with Technical Regulations for Commercial Pig Production for Intensive Pig Farms (GB/T 17824.22008). The experimental protocol was approved by the Animal Ethics Committee of Nanjing Agricultural University, with the project number 2012CB124703. The slaughter and sampling procedures complied with the "Guidelines on Ethical Treatment of Experimental Animals" (2006) No. 398 set by the Ministry of Science and Technology, China.

Determination of GR $m R N A$ and protein: Hippocampal samples were ground in liquid nitrogen. RNA, DNA and protein were separated according to a paper published previously [20].

After pretreated with RNase-free DNase, $2 \mu \mathrm{g}$ of total RNA was reverse-transcribed to cDNA in obedience to the protocol provided in the random hexamer primers kit (Promega, Madison, WI, U.S.A.). Two $\mu l$ of diluted cDNA (1:25, $\mathrm{vol} / \mathrm{vol})$ was used for real-time PCR which was performed with a Mx3000P Real-Time PCR System (Stratagene, Santa Clara, CA, U.S.A.). All the primers, synthesized by Generay Biotech, for determining GR total mRNA and its variants and internal control ( $\beta$-actin) are listed in Table 2. Data analysis conformed to the method of $2^{-\Delta \Delta C T}$ [23]. The abundance of GR variants mRNA was presented as the percentage of total GR mRNA in control group.

Protein samples, after being measured concentrations with a Pierce BCA Protein Assay kit (No. 23225, Thermo, Rockford, IL, U.S.A.), were denatured in waterbath for $5 \mathrm{~min}$ at $100^{\circ} \mathrm{C}$ and seperated in a $7.5 \%$ or $10 \%$ SDS-PAGE. After protein transfer, nitrocellulose membranes (BioTrace, Pall Co., Ann Arbor, MI, U.S.A.) were blocked with 4\% BSA and incubated respectively with anti-GR (sc-1004, Santa Cruz Biotechnology, Dallas, TX, U.S.A., 1:500) and anti-ACTB (AP0060, Bioworld, Atlanta, GA, U.S.A., 1:10,000) antibodies overnight at $4^{\circ} \mathrm{C}$. Bands were visualized by enhanced chemiluminescence with the LumiGlo substrate (Super Signal West Pico Trial Kit, Pierce, Rockford, IL, U.S.A.) and captured by VersaDoc 4000MP system (Bio-Rad, Hercules, CA, U.S.A.) to calculate the value of band density using Quantity
Table 1. Composition and nutrient content of the experimental diet

\begin{tabular}{lcc}
\hline & Control & Betaine \\
\hline Ingredient, g/kg & 370 & 370 \\
Corn & 300 & 300 \\
Wheat & 80 & 80 \\
Bran & 170 & 170 \\
Soybean meal & 30 & 30 \\
Lignocelluloses & 20 & 20 \\
CaHPO $_{4}$ & 8 & 8 \\
Soybean oil & 20 & 20 \\
Premix* & 0 & 3 \\
Betaine & 13.1 & 13.1 \\
Digestible energy, MJ/kg & & \\
Calculated composition & 15 & 15 \\
Crude protein, \% & 4.5 & 4.5 \\
Crude fiber, \% & 0.84 & 0.84 \\
Calcium, \% & 0.65 & 0.65 \\
Phosphorous, \% & & \\
\hline
\end{tabular}

* The premix contains (per kg): vitamin A: 240,000 IU; vitamin D3: 60,000 IU; vitamin E: $720 \mathrm{IU}$; vitamin K3: $30 \mathrm{mg}$; vitamin B1: $30 \mathrm{mg}$; vitamin B2: $120 \mathrm{mg}$; vitamin B6: $60 \mathrm{mg}$; vitamin B12: $360 \mathrm{mg}$; niacin: 600 $\mathrm{mg}$; pantothenic acid: $300 \mathrm{mg}$; folic acid: $6 \mathrm{mg}$; manganese sulphate: 1.0 $\mathrm{g}$; zinc oxide: $2.5 \mathrm{~g}$; iron sulphate: $4.0 \mathrm{~g}$; copper sulphate: $4.0 \mathrm{~g}$; sodium selenite: $6 \mathrm{mg}$; calcium: $150 \mathrm{~g}$; phosphorus: $15 \mathrm{~g}$; sodium chloride: $40 \mathrm{~g}$.

One software (Bio-Rad) automatically. The protein content was presented as the fold change relative to the control.

Methylated DNA immunoprecipitation analysis: Hippocampal genomic DNA was sonicated into fragements approximately $500 \mathrm{bp}$ in size. Two $\mu \mathrm{g}$ of sonicated DNA were denatured and incubated with the antibody against 5-methyl cytosine (ab10805, Abcam, Cambridge, MA, U.S.A.) to immunoprecipitate the methylated DNA fragments. Then, protein $\mathrm{G}$ agarose beads were used to capture the DNA-antibody complex which was washed and treated with proteinase $\mathrm{K}$ to release the precipitated DNA. The MeDIP DNA was then extracted, purified and used to amplify the fragment of GR promoter by real-time PCR, following the procedure described previously [20]. The promoter region of ACTB gene containing no $\mathrm{CpG}$ sites was amplified to serve as a negative control in MeDIP analysis. All primers used in the present study are shown in Table 2. Data were normalized against the negative control and presented as the fold change relative to the average value of the control group.

Prediction and determination of miRNAs: The potential miRNAs targeting the 3' UTR of GR mRNA were predicted with the Probability of Interaction by Target Accessibility (PITA) algorithm [17] based on the online database of pig microRNAs (http://www.mirbase.org/), using microRNA prediction tool (http://genie.weizmann.ac.il/pubs/mir07/ mir07_prediction.html).

Two $\mu \mathrm{g}$ of total RNA from each piglet were polyadenylated by poly(A) polymerase (PAP) at $37^{\circ} \mathrm{C}$ for $1 \mathrm{hr}$ using a Poly(A) Tailing Kit (AM1350; Ambion, Rockford, IL, U.S.A.), according to the manufacturer's instructions. After phenol/chloroform extraction and ethanol precipitation, treated RNA was then dissolved and reverse-transcribed using poly $(\mathrm{T})$ adapter and M-MLV (Promega). Real-time PCR was performed in 
Table 2. Primers for real-time PCR amplification of GR mRNA and its variants, segments of GR promoter

\begin{tabular}{|c|c|c|c|}
\hline Target gene & $\begin{array}{l}\text { Product length } \\
\text { (bp) }\end{array}$ & $\begin{array}{c}\text { Primer sequence } \\
\text { (F: forward, R: reverse) }\end{array}$ & Reference \\
\hline \multirow[t]{2}{*}{ GR } & 108 & F: 5'-CCAAACTCTGCCTTGTGTGTTC-3' & AY779185 \\
\hline & & R: 5'- TGTGCTGTCCTTCCACTGCT-3' & \\
\hline \multirow[t]{2}{*}{ GR 1-4 } & 161 & F: 5'-CACACAGCACAACCTTTC-3' & \\
\hline & & R: 5'-AACCTTCACAGGAGTTCC-3' & \\
\hline \multirow[t]{2}{*}{ GR 1-5 } & 207 & F: 5'-GCGTGCAACTTCCTTCAA-3' & \\
\hline & & R: 5'-CTTGGAGTCTGGCTGAGA-3' & \\
\hline \multirow[t]{2}{*}{ GR 1-6 } & 189 & F: 5'-GAGTGGGCCGCCCAGACGAT-3' & \\
\hline & & R: 5'-CCCCCCCTCAGGCTTTTAT-3' & \\
\hline \multirow[t]{2}{*}{ GR 1-7 } & 185 & F: 5'-GCGAAGAGAAACTAGAGAAA-3' & \\
\hline & & R: 5'-AACCTTCACAGGAGTTCC-3' & \\
\hline \multirow[t]{2}{*}{ GR 1-8 } & 144 & F: 5'-TGCCCAGCGTCGCCAACA-3' & \\
\hline & & R: 5'-CCGCCCCTCAGGCTTTTAT-3' & \\
\hline \multirow[t]{2}{*}{ GR $1-9,10$} & 177 & F: 5'-CCTGCTTTCACACGCTAA-3' & \\
\hline & & R: 5'-ATCACATGGGCTCTCTCC-3' & \\
\hline \multirow[t]{2}{*}{ GR 1-11 } & 163 & F: 5'-CTGGTGGAAGTGGGCGTGTC-3' & \\
\hline & & R: 5'-TTCCTCCCCTCAGGCTTTTAT-3' & \\
\hline \multirow[t]{2}{*}{$\beta$-actin } & 201 & F: 5'-CCCACGGAATCGAGAAAGAG-3' & AF057040 \\
\hline & & R: 5'-TTGACGGAAGGGCACCA-3' & \\
\hline \multirow[t]{2}{*}{ GR segment1 } & & F: 5'-CGGCGAAGGTCTAGGTACG-3' & \\
\hline & & R: 5'- GAAGGCTGCCCCGTGT-3' & \\
\hline \multirow[t]{2}{*}{ GR segment2 } & & F: 5'- TCTTTGAACCCCGCACTT-3' & \\
\hline & & R: 5'- CTCCCAGCGACAAACCAG-3' & \\
\hline Negative control & & F: 5'- CTGGGCATCAGAACCTGT-3' & \\
\hline (ACTB promoter) & & R: 5'- GAGCAATCCCCTGAAGAA-3' & \\
\hline
\end{tabular}

Table 3. Primers for real-time PCR amplification of miRNAs

\begin{tabular}{ll}
\hline \multicolumn{1}{c}{ Primer } & Primer sequence \\
\hline miR-18b & 5'-TAAGGTGCATCTAGTGCAGTTAG-3' \\
miR-22-3p & 5'-AAGCTGCCAGTTGAAGAACTGT-3' \\
miR-22-5p & 5'-AGTTCTTCAGTGGCAAGCTTTA-3' \\
miR-30a-3p & 5'-CTTTCAGTCGGATGTTTGCAGC-3' \\
miR-30a-5p & 5'-TGTAAACATCCTCGACTGGAAG-3' \\
miR-130b & 5'-CAGTGCAATGATGAAAGGGCAT-3' \\
miR-138 & 5'-AGCTGGTGTTGTGAATCAGGC-3' \\
miR-181a & 5'-AACATTCAACGCTGTCGGTGAGTT-3' \\
miR-183 & 5'-TATGGCACTGGTAGAATTCACTG-3' \\
miR-181d & 5'-CCCACCGAGGGATGAATGTCAC-3' \\
miR-181c & 5'-AACATTCAACCTGTCGGTGAGT-3' \\
universal reverse primer & 5'-TAGAGTGAGTGTAGCGAGCA-3' \\
U6 & 5'-GGCAAGGATGACACGCAAAT-3' \\
Poly (T) adapter & 5'-TAGAGTGAGTGTAGCGAGCACAGAATTAATACG \\
& ACTCACTATAGGTTTTTTTTTTTTTTVN-3' \\
\hline
\end{tabular}

an MX3000P (Stratagene) with SYBR_Premix Ex TaqTM II (TaKaRa, Otsu, Japan) using a miRN̄A-specific forward primer and a universal reverse primer complementary to part of the poly $(\mathrm{T})$ adapter sequence. U6 was chosen as a reference gene to normalize the technical variations. The sequences for all the primers and the poly $(\mathrm{T})$ adapter are listed in Table 3. The abundance of miRNAs was presented as the fold change relative to the average value of the control group.

Functional validation of miR-130b and miR-181d: Dual luciferase activity assay was used to verify the function of
miR-130b and miR-181d targeting GR 3'UTR in vitro, as previously described [26]. Briefly, fragments of miR-130b and miR-181d precursor and the scramble control (SC) sequences (Table 4) were subcloned to construct plasmids named pSilence-miR-130b, pSilence-miR-181d and pSilence-miR-SC, respectively (Fig. 3A). GR 3' UTR sequence was amplified by PCR using the specific primers (Table 4), and the product was then subcloned to pGL3-Control using XbaI (Invitrogen, Rockford, IL, U.S.A.) to construct the pGL3-GR-UTR plasmid (Fig. 3B). HeLa cells were trans- 
Table 4. Nucleotides sequences used in functional validation of miRNAs

\begin{tabular}{|c|c|}
\hline Name & Sequences (F, forward; $\mathrm{R}$, reverse) \\
\hline \multirow[t]{2}{*}{ miR-130b precursor } & $\begin{array}{l}\text { F:5’- GATCCCCTTGGCATAACGTAGCAGCACATAATGGTTTGTGGGTTTTGAAAAGGTGCAGGCCATATT } \\
\text { GTGCTGCCTCAAAAATACAAGGTTTTTTGGAAA-3' }\end{array}$ \\
\hline & $\begin{array}{l}\text { R:5'- AGCTTTTCCAAAAAAGCCTGACTGATGCCCTTTCATCATTGCACTGCTTCCCAGTGGCCCACAGTA } \\
\text { GTGCAACAGGGAAAGAGTGTCAGGCAGGCG-3' }\end{array}$ \\
\hline \multirow[t]{2}{*}{ miR-181d precursor } & F:5’- TGCTGCCCACCGAGGGATGAATGTCACGTTTTGGCCACTGACTGACGTGACATTTCCCTCGGTGGG-3' \\
\hline & R:5'- CCTGCCCACCGAGGGAAATGTCACGTCAGTCAGTGGCCAAAACGTGACATTCATCCCTCGGTGGGC-3' \\
\hline \multirow[t]{2}{*}{$\mathrm{miR}-\mathrm{SC}$} & $\begin{array}{l}\text { F:5'- GATCCGACTTACAGCCAGTTCCTAGTATAGTGAAGCAGCAGATGGTATACTAGGAACTGGCTGTAA } \\
\text { GCTTTTTTTGGAAA-3' }\end{array}$ \\
\hline & $\begin{array}{l}\text { R:5'- AGCTTTTCCAAAAAAAGCTTACAGCCAGTTCCTAGTATACCATCTGCTGCTTCACTATACTAGGAA } \\
\text { CTGGCTGTAAGTCG-3' }\end{array}$ \\
\hline \multirow[t]{2}{*}{ GR 3’UTR primer } & F:5'- TCTAGACTTTCGTTGGTGTAT-3' \\
\hline & R:5'- TCTAGAGCAAACCCATTGGG-3' \\
\hline
\end{tabular}

fected with the plasmids with an electroporation device, and pRL-TK was used to normalize the transformation efficiency. After $24 \mathrm{hr}$ incubation at $5 \% \mathrm{CO}_{2}$ and $37^{\circ} \mathrm{C}$, firefly and renilla luciferase activities were measured, and the targeting efficacy of miRNAs in post-transcriptional repression of reporter protein was presented as the fold change relative to the average value of the pSilence-miR-SC.

Statistical analysis: All data were expressed as means \pm SEM and analyzed with one-way ANOVA for independent samples with Statistical Packages for the Social Sciences (SPSS) 11.0 for Windows. Differences were considered significant when $P \leq 0.05$.

\section{RESULTS}

Expression of total GR $m R N A$ and the alternative exon 1 $m R N A$ variants, as well as the total protein content of $G R$ : As shown in Fig. 1, the hippocampal expression of total GR mRNA was significantly higher $(P<0.01)$ in offspring piglets born to betaine-treated sows. Seven alternative GR exon 1 mRNA variants were detected in the hippocampus of newborn piglets. But, only GR 1-4 $(P<0.05)$ and GR 1-9,10 $(P<0.01)$ mRNA variants were significantly upregulated in betaine group. Nevertheless, no significant alteration was observed in total GR protein content as revealed by Westernblot analysis (Fig. 1).

Methylation level of GR promoter sequences: Two segments of GR promoter, $-4861 \sim-4722$ and $-1650 \sim-1515$ from translation start codon (ATG), were analyzed using MeDIP assay. The sequences of these two segments and the position relative to GR exon 1 variants are shown in Fig. 2. Data from MeDIP analysis indicated that the methylation level of segment $1(-4861 \sim-4722)$ was not significantly changed, but segment $2(-1650 \sim-1515)$ was hypermethylated $(P<0.05)$ in betaine group (Fig. 2). The transcription factor prediction analysis with $\mathrm{PATCH}^{\mathrm{TM}}$ (http://www. gene-regulation.com/cgi-bin/pub/programs/patch/bin/patch. cgi) showed many potential transcription factor binding sites within this segment (Fig. 2).

Expression of miRNAs targeting GR: The abundance of miR-181a $(P<0.05)$, miR-181d $(P<0.01)$ and miR-130b $(P<0.05)$ was significantly higher in the hippocampus of be- taine-treated piglets compared to control counterparts (Table 5). No significant difference was detected for the expression of miR-18b, 22-3p/5p, 30a-3p/5p, 138, 183 or $181 \mathrm{c}$ between control and betaine-treated groups.

Functional validation of miR-130b and miR-181d: The schematic maps of the ssc-miR-130b and ssc-miR-181d over-expression plasmids, as well as the luciferase reporter plasmid containing $1384 \mathrm{bp}$ of pig GR 3' UTR, are shown in Fig. 3A and 3B, respectively. Overexpression of miR-130b $(P<0.05)$ or miR-181d $(P<0.01)$ was able to significantly reduce the luciferase activity of HeLa cells transfected with the pig GR 3'UTR reporter plasmid, as compared with the scramble control (Fig. 3C).

\section{DISCUSSION}

It is well-documented that GR expression can be modulated by maternal nutritional interventions, such as protein restriction in rats $[4,21]$ and undernutrition in sheep [2], as well as dietary supplementation of methyl donors in rats [10] and in humans [12]. Moreover, infusion of L-methionine diminished hippocampal GR expression in the adult rat offspring of high licking/grooming and arched-back nursing (LG-ABN) mothers [37]. Similarly, maternal dietary supplementation with methyl donor mixture inhibited hippocampal GR expression in three-month-old tame rats [11]. In the present study, however, maternal betaine supplementation increased total GR mRNA expression in the hippocampus of newborn piglets. The diverse responses of hippocampal GR expression to maternal methyl donor supplementation may attribute to multiple factors, such as the type and the dose of the substances, the timing and the duration of supplementation, the species, genotype and the age of the animals investigated. Moreover, the distribution patterns of GR exon 1 mRNA variants differ significantly between species. In pigs, GR mRNA variants, 1-4, 1-6 and 1-9,10, are abundantly expressed and tightly regulated in the hippocampus [29, 31], while in rats, GR 1-7 appears to be the most important mRNA variant of functional significance in hippocampus [15]. Therefore, it is presumed that the transcriptional regulation of GR expression in hippocampus is complex and species-specific. In our experiment, significant 


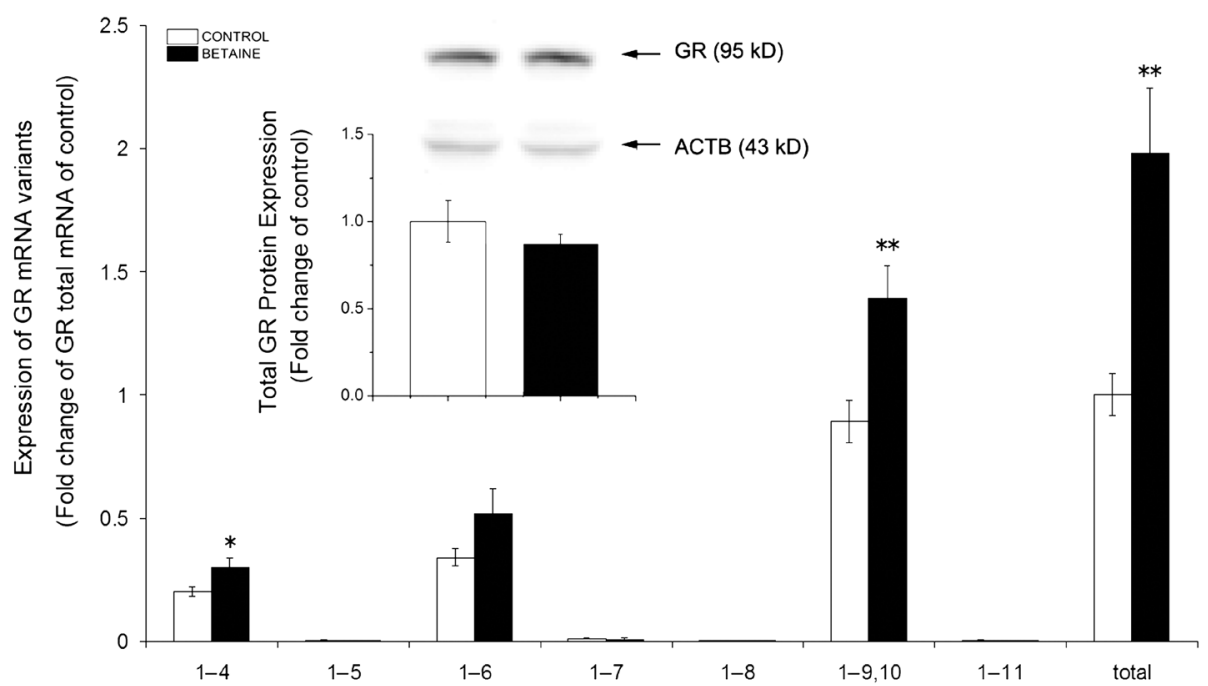

Fig. 1. RT-PCR demonstrated that hippocampal expression of GR exon 1-4 and 1-9,10 mRNA was higher in betaine-treated group, associated with the higher total GR mRNA. Meanwhile, western blotting analysis showed that total GR protein content was not changed so much. Values are means, with their standard errors, and $*$ indicates significant difference between groups at $P<0.05, * *$ means at $P<0.01$.

Segment 1

CTTCTCTTTTCCCAGGCGGGGGCTTCGCTTCCTTITCC AAGATGGCGGCCCCGGGGTCATCTGGGGGCGGCCGTGC AGATTGCCTCGGGACAGGGGGCTTGCTGGTAGCCCAGTT CTCTCCTGTCACCTCAGATGAC

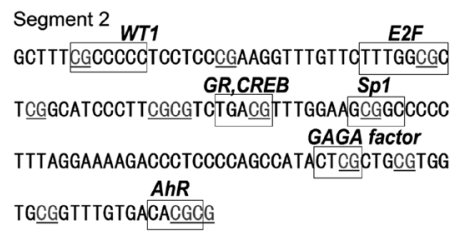

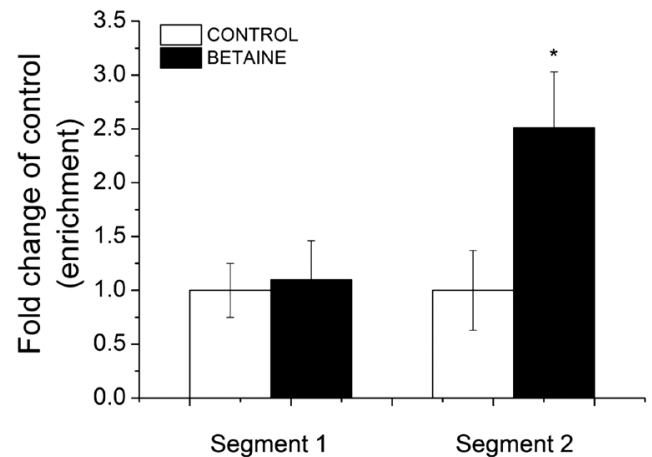

Segment 2

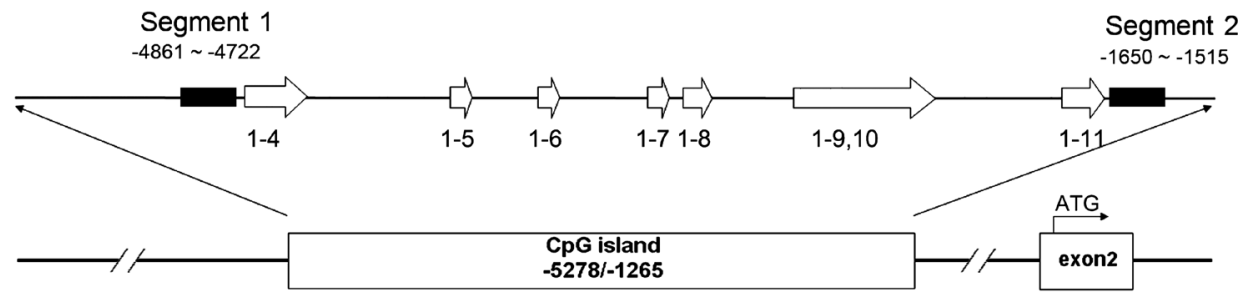

Fig. 2. CpG sites are underlined in detectable segment1 (-4861 -4722) and segment2 (-1650 -1515) from translation start codon (ATG), which were marked as block in GR exon 1 structure diagram (blank arrow). Predicted transcription factor binding sites among segment 2 were framed. MeDIP results are presented in column figure, showing DNA methylation status of CpGs in segment 2 was increased. Values are means, with their standard errors, and * indicates significant difference between groups at $P<0.05$.

change of hippocampal GR expression in mRNA level was observed with maternal betaine treatment, but not in protein level. Probably, potential participant of transcript regulation, such as DNA methylation and miRNAs, was also induced by maternal betaine to maintain GR protein homeostasis in the hippocampi of these piglets.
The effects of maternal methyl donors on the regulation of GR transcription often involve changes of the methylation status in GR promoter regions. Higher choline intake led to hypermethylation of 5' untranslated exon 1F (homologue of exon 1-7 in rats) of GR promoter in human placenta [12], while methionine treatment reversed the hypomethylation of 


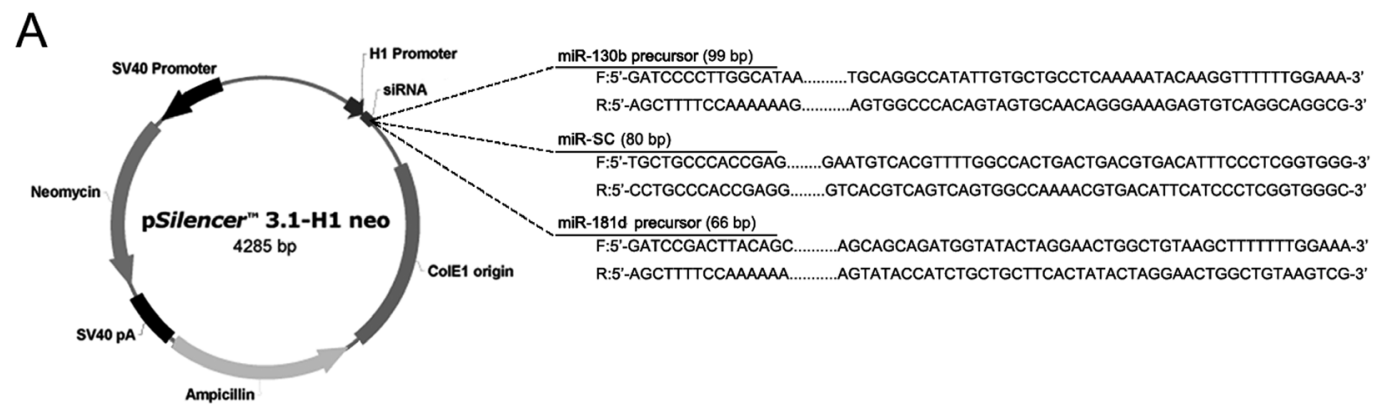

B

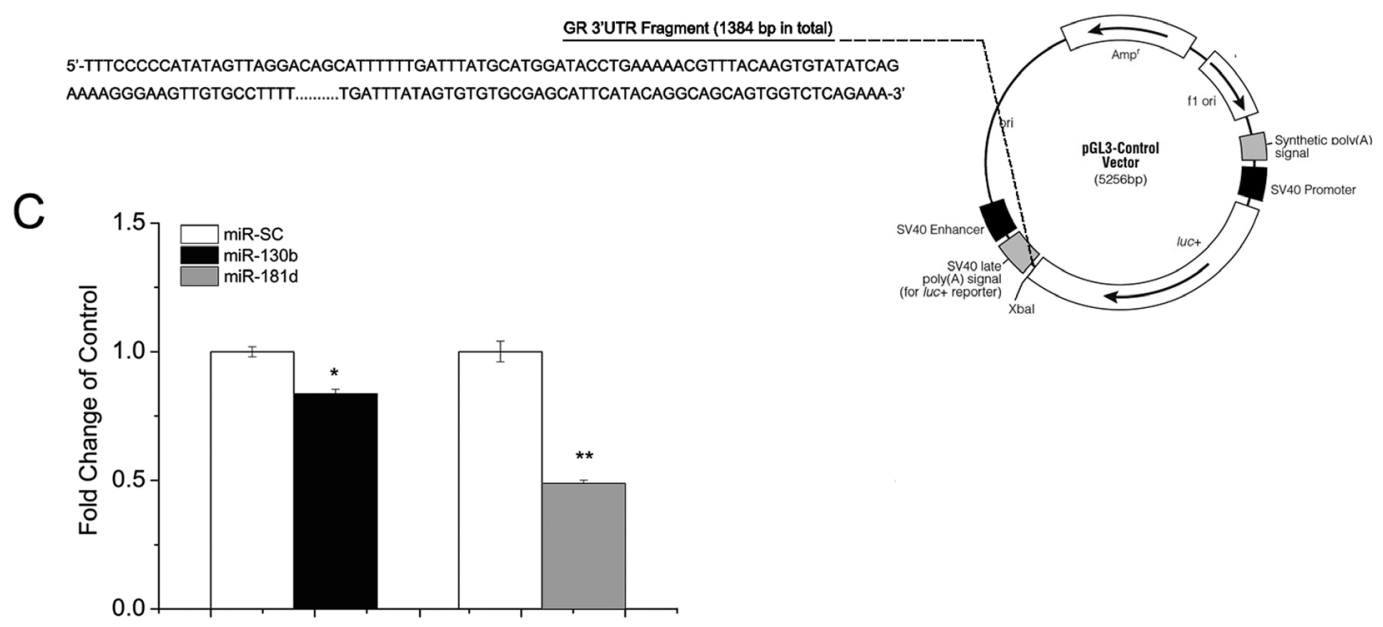

Fig. 3. (A) Plasmid structure containing miR-130b and miR-181d and control sequences. Cloning region is indicated in dot line with respective miRNAs and control sequence. Original structure of pSilencer ${ }^{\mathrm{TM}} 3.1-\mathrm{H} 1$ neo is cited from manual of the Kit. (B) Plasmid structure containing GR 3'UTR sequences. Cloning region is indicated in dot line with GR 3'UTR sequences (1,384 bp). Original structure of pGL3-Control Vector is cited from manual of the Kit. (C) Statistic results of the data from dual luciferase activity assay system. Values are means, with their standard errors. *and ** indicate significant difference between groups at $P<0.05$ and $P<0.01$, respectively.

Table 5. Expression of miRNAs targeting porcine GR 3'UTR

\begin{tabular}{lccc}
\hline Predicted miRNAs & Control $(\mathrm{n}=5)$ & Betaine $(\mathrm{n}=5)$ & $P$-value \\
\hline miR-130b & $1.00 \pm 0.09$ & $1.35 \pm 0.09$ & 0.03 \\
miR-138 & $1.00 \pm 0.06$ & $1.10 \pm 0.06$ & 0.26 \\
miR-18b & $1.00 \pm 0.09$ & $1.09 \pm 0.10$ & 0.50 \\
miR-181a & $1.00 \pm 0.06$ & $1.22 \pm 0.06$ & 0.04 \\
miR-181c & $1.00 \pm 0.08$ & $1.07 \pm 0.09$ & 0.61 \\
miR-181d & $1.00 \pm 0.41$ & $3.08 \pm 0.14$ & 0.00 \\
miR-183 & $1.00 \pm 0.13$ & $1.29 \pm 0.14$ & 0.16 \\
miR-22-3p & $1.00 \pm 0.06$ & $1.07 \pm 0.09$ & 0.51 \\
miR-22-5p & $1.00 \pm 0.10$ & $1.10 \pm 0.11$ & 0.54 \\
miR-30a-3p & $1.00 \pm 0.09$ & $1.04 \pm 0.05$ & 0.71 \\
miR-30a-5p & $1.00 \pm 0.07$ & $1.12 \pm 0.06$ & 0.26 \\
\hline
\end{tabular}

Mean values with their standard errors.

the exon 1-7 GR promoter in the hippocampus of adult rat offspring of high LG-ABN mothers, as revealed with sodium bisulfite sequencing technique [37]. Nevertheless, it was also reported that feeding methyl-supplemented diet [10] or methyl donor deficiency diet [18] to pregnant dams did not alter the methylation level of GR exon 1-7 promoter in the hippocampus of rat offspring. These results suggest that the maternal or prenatal supplementation of methyl donors has minor, if any, effects on methylation status of GR exon 1-7 promoter in the hippocampus of rat offspring. In the present study, only two segments in the region of porcine GR promoter were investigated, and the segment $(-1650 \sim-1515)$ was found to be hypermethylated in the hippocampus of maternal betaine-treated piglets. The other regions can not be amplified due to extremely high enrichment of CpGs. Certainly, more detailed and higher resolution analysis of methylation pattern across the whole region of GR promoter is required, by using more powerful techniques, to elucidate the role of $\mathrm{CpG}$ methylation in the transcription regulation of different GR mRNA variants.

It is well known that DNA hypermethylation in gene promoter is functioned for suppression of mRNA expression when positive transcript factors can not bind to the corresponding sequences. Otherwise, binding loss of negative transcript factor would contributed to promoting mRNA ex- 
pression, as we previously reported that hypermethylation of differentially methylated regions in IGF2 gene promoter was associated with high expression of IGF2 mRNA [20]. Here, we found that the segment $(-1650 \sim-1515)$ of GR gene promoter was hypermethylated, which might co-work with negative transcript factors to improve GR mRNA expression. The segment $(-1650 \sim-1515)$ is located upstream of the translation start codon (ATG) in exon 2, which contains multiple transcription factor binding sites (Fig. 2), predicted to be involved in the transcriptional regulation of GR expression. Therefore, feeding betaine-supplemented diet to pregnant sows modulated hippocampal GR transcription in neonatal offspring piglets through, at least partly, alterations of methylation status in GR promoter.

GR expression is also regulated at the post-transcriptional level. In this study, the increased abundance of total GR, as well as its 1-4, and 1-9,10 mRNA variants, did not lead to significant change in the level of GR protein in the hippocampus of betaine-treated piglets. We presumed that there might be miRNA-mediated post-transcriptional regulation involved. Methyl donor deficiency (MDD) in utero caused growth retardation of rat fetus at embryonic day 20 associated with upregulated expression of the Stat3 regulator miR-124 [16]. We reported previously that feeding betaine-supplemented diet to pregnant sows significantly altered hepatic expression of miR-497 and miR-181 in neonatal offspring piglets [5]. In this study, hippocampal expression of miR-130b, miR-181a and miR-181d was significantly up-regulated in neonatal piglets of betaine group. Overexpression of miR-130b was reported to decrease the expression of endogenous GR protein and the activity of the luciferase reporter containing the 3'UTR of human GR mRNA in GC-sensitive MM.1S cells [32]. In the present study, the suppressive function of ssc-miR-130b and ssc-miR-181d on GR expression was validated in HeLa cells transfected with a luciferase reporter plasmid containing pig GR 3'UTR sequence. miR-181d was previously reported to target methyl-guanine-methyl-transferase gene in human [40] and was implicated to be a potential target for glioma therapy [19]. Furthermore, miR-181d was found to be one of the stress-responsive miRNAs which may target a number of stress and metabolic signaling pathways in thymocytes [3]. However, direct evidences to support the suppressive effect of miR-181d on GR expression are lacking. To our knowledge, here, we provide the first evidence that ssc-miR$181 \mathrm{~d}$ is able to target porcine GR 3'UTR and suppress the luciferase reporter activity in HeLa cells.

In conclusion, we demonstrate, for the first time, that maternal betaine supplementation during gestation enhances the expression of total GR mRNA, as well as its exon 1-4 and 1-9,10 mRNA variants, in the hippocampus of neonatal piglets, without affecting the total cellular GR protein content. Alterations of $\mathrm{CpG}$ methylation in the proximal region of GR promoter and modified expression of miRNAs targeting 3'UTR of porcine GR mRNA appear to be involved in the regulation of hippocampal GR expression. Long-term follow-up studies are required to evaluate the possible consequences of maternal betaine supplementation regarding the health and performance of pigs in later life.
ACKNOWLEDGMENTS. This work was supported by the National Basic Research Program of China (2012CB124703), the Major National Science \& Technology Program (2009ZX08009-138B), the Special Fund for Agro-scientific Research in the Public Interest (201003011), the Fundamental Research Funds for the Central Universities (KYZ200913) and the Priority Academic Program Development of Jiangsu Higher Education Institutions (PAPD). The funders had no role in study design, data collection and analysis, decision to publish or preparation of the manuscript.

\section{REFERENCES}

1. Anderson, O. S., Sant, K. E. and Dolinoy, D. C. 2012. Nutrition and epigenetics: an interplay of dietary methyl donors, onecarbon metabolism and DNA methylation. J. Nutr. Biochem. 23: 853-859. [Medline] [CrossRef]

2. Begum, G., Davies, A., Stevens, A., Oliver, M., Jaquiery, A., Challis, J., Harding, J., Bloomfield, F. and White, A. 2013. Maternal undernutrition programs tissue-specific epigenetic changes in the glucocorticoid receptor in adult offspring. Endocrinology 154: 4560-4569. [Medline] [CrossRef]

3. Belkaya, S. and van Oers, N. S. 2014. Transgenic expression of microRNA-181d augments the stress-sensitivity of $\mathrm{CD}^{+} \mathrm{CD}^{+}$ thymocytes. PLoS ONE 9: e85274. [Medline] [CrossRef]

4. Bertram, C., Trowern, A. R., Copin, N., Jackson, A. A. and Whorwood, C. B. 2001. The maternal diet during pregnancy programs altered expression of the glucocorticoid receptor and type 211 beta-hydroxysteroid dehydrogenase: potential molecular mechanisms underlying the programming of hypertension in utero. Endocrinology 142: 2841-2853. [Medline]

5. Cai, D., Jia, Y., Lu, J., Yuan, M., Sui, S., Song, H. and Zhao, R. 2014. Maternal dietary betaine supplementation modifies hepatic expression of cholesterol metabolic genes via epigenetic mechanisms in newborn piglets. Br. J. Nutr. 112: 1459-1468. [Medline] [CrossRef]

6. Chen, F., Watson, C. S. and Gametchu, B. 1999. Multiple glucocorticoid receptor transcripts in membrane glucocorticoid receptor-enriched S-49 mouse lymphoma cells. J. Cell. Biochem. 74: 418-429. [Medline] [CrossRef]

7. Daskalakis, N. P. and Yehuda, R. 2014. Site-specific methylation changes in the glucocorticoid receptor exon $1 \mathrm{~F}$ promoter in relation to life adversity: systematic review of contributing factors. Front. Neurosci. 8: 369. [Medline] [CrossRef]

8. Eklund, M., Bauer, E., Wamatu, J. and Mosenthin, R. 2005. Potential nutritional and physiological functions of betaine in livestock. Nutr. Res. Rev. 18: 31-48. [Medline] [CrossRef]

9. Gądek-Michalska, A., Spyrka, J., Rachwalska, P., Tadeusz, J. and Bugajski, J. 2013. Influence of chronic stress on brain corticosteroid receptors and HPA axis activity. Pharmacol. Rep. 65: 1163-1175. [Medline] [CrossRef]

10. Herbeck, Y. E., Gulevich, R. G., Amelkina, O. A., Plyusnina, I. Z. and Oskina, I. N. 2010. Conserved methylation of the glucocorticoid receptor gene exon 1(7) promoter in rats subjected to a maternal methyl-supplemented diet. Int. J. Dev. Neurosci. 28: 9-12. [Medline] [CrossRef]

11. Herbeck, Y. E., Os'kina, I. N., Gulevich, R. G. and Plyusnina, I. Z. 2010. Effects of maternal methyl-supplement diet on hippocampal glucocorticoid receptor mRNA expression in rats selected for behavior. Cytol. Genet. 44: 108-113. [CrossRef]

12. Jiang, X., Yan, J., West, A. A., Perry, C. A., Malysheva, O. V., Devapatla, S., Pressman, E., Vermeylen, F. and Caudill, M. A. 2012. Maternal choline intake alters the epigenetic state of fetal cortisol-regulating genes in humans. FASEB J. 26: 3563-3574. 
[Medline] [CrossRef]

13. Jiang, Z., Qian, L., Zou, H., Jia, Y., Ni, Y., Yang, X., Jiang, Z. and Zhao, R. 2014. Porcine glucocorticoid receptor (NR3C1) gene: tissue-specificity of transcriptional strength and glucocorticoid responsiveness of alternative promoters. J. Steroid Biochem. Mol. Biol. 141: 87-93. [Medline] [CrossRef]

14. Joëls, M., Verkuyl, J. M. and Van Riel, E. 2003. Hippocampal and hypothalamic function after chronic stress. Ann. N. Y. Acad. Sci. 1007: 367-378. [Medline] [CrossRef]

15. Ke, X., Schober, M. E., McKnight, R. A., O'Grady, S., Caprau, D., Yu, X., Callaway, C. W. and Lane, R. H. 2010. Intrauterine growth retardation affects expression and epigenetic characteristics of the rat hippocampal glucocorticoid receptor gene. Physiol. Genomics 42: 177-189. [Medline] [CrossRef]

16. Kerek, R., Geoffroy, A., Bison, A., Martin, N., Akchiche, N., Pourié, G., Helle, D., Guéant, J. L., Bossenmeyer-Pourié, C. and Daval, J. L. 2013. Early methyl donor deficiency may induce persistent brain defects by reducing Stat 3 signaling targeted by miR-124. Cell Death Dis. 4: e755. [Medline] [CrossRef]

17. Kertesz, M., Iovino, N., Unnerstall, U., Gaul, U. and Segal, E. 2007. The role of site accessibility in microRNA target recognition. Nat. Genet. 39: 1278-1284. [Medline] [CrossRef]

18. Konycheva, G., Dziadek, M. A., Ferguson, L. R., Krägeloh, C. U., Coolen, M. W., Davison, M. and Breier, B. H. 2011. Dietary methyl donor deficiency during pregnancy in rats shapes learning and anxiety in offspring. Nutr. Res. 31: 790-804. [Medline] [CrossRef]

19. Li, R., Li, X., Ning, S., Ye, J., Han, L., Kang, C. and Li, X. 2014. Identification of a core miRNA-pathway regulatory network in glioma by therapeutically targeting miR-181d, miR-21, miR-23b, $\beta$-Catenin, CBP, and STAT3. PLOS ONE 9: e101903. [Medline] [CrossRef]

20. Li, X., Sun, Q., Li, X., Cai, D., Sui, S., Jia, Y., Song, H. and Zhao, R. 2015. Dietary betaine supplementation to gestational sows enhances hippocampal IGF2 expression in newborn piglets with modified DNA methylation of the differentially methylated regions. Eur. J. Nutr. 54: 1201-1210. [Medline] [CrossRef]

21. Lillycrop, K. A., Phillips, E. S., Jackson, A. A., Hanson, M. A. and Burdge, G. C. 2005. Dietary protein restriction of pregnant rats induces and folic acid supplementation prevents epigenetic modification of hepatic gene expression in the offspring. J. Nutr. 135: 1382-1386. [Medline]

22. Lillycrop, K. A., Slater-Jefferies, J. L., Hanson, M. A., Godfrey, K. M., Jackson, A. A. and Burdge, G. C. 2007. Induction of altered epigenetic regulation of the hepatic glucocorticoid receptor in the offspring of rats fed a protein-restricted diet during pregnancy suggests that reduced DNA methyltransferase- 1 expression is involved in impaired DNA methylation and changes in histone modifications. Br. J. Nutr. 97: 1064-1073. [Medline] [CrossRef]

23. Livak, K. J. and Schmittgen, T. D. 2001. Analysis of relative gene expression data using real-time quantitative PCR and the 2(-Delta Delta C(T)) Method. Methods 25: 402-408. [Medline] [CrossRef]

24. Massart, R., Mongeau, R. and Lanfumey, L. 2012. Beyond the monoaminergic hypothesis: neuroplasticity and epigenetic changes in a transgenic mouse model of depression. Philos. Trans. $R$. Soc. Lond. B Biol. Sci. 367: 2485-2494. [Medline] [CrossRef]

25. McCormick, J. A., Lyons, V., Jacobson, M. D., Noble, J., Diorio, J., Nyirenda, M., Weaver, S., Ester, W., Yau, J. L., Meaney, M. J., Seckl, J. R. and Chapman, K. E. 2000. 5'-heterogeneity of glucocorticoid receptor messenger RNA is tissue specific: differential regulation of variant transcripts by early-life events. Mol. Endocrinol. 14: 506-517. [Medline]

26. Pan, S., Zheng, Y., Zhao, R. and Yang, X. 2013. MicroRNA-130b and microRNA-374b mediate the effect of maternal dietary protein on offspring lipid metabolism in Meishan pigs. Br. J. Nutr.
109: 1731-1738. [Medline] [CrossRef]

27. Peters, A. 2011. The selfish brain: Competition for energy resources. Am. J. Hum. Biol. 23: 29-34. [Medline] [CrossRef]

28. Ratriyanto, A., Mosenthin, R., Bauer, E. and Eklund, M. 2009. Metabolic, Osmoregulatory and Nutritional Functions of Betaine in Monogastric Animals. Asian Austral. J. Anim. 22: 1461-1476. [CrossRef]

29. Reyer, H., Ponsuksili, S., Wimmers, K. and Murani, E. 2013. Transcript variants of the porcine glucocorticoid receptor gene (NR3C1). Gen. Comp. Endocrinol. 189: 127-133. [Medline] [CrossRef]

30. Russcher, H., Dalm, V. A., de Jong, F. H., Brinkmann, A. O., Hofland, L. J., Lamberts, S. W. and Koper, J. W. 2007. Associations between promoter usage and alternative splicing of the glucocorticoid receptor gene. J. Mol. Endocrinol. 38: 91-98. [Medline] [CrossRef]

31. Sun, Q., Jia, Y., Li, R., Li, X., Yang, X. and Zhao, R. 2014. Breedspecific expression of GR exon 1 mRNA variants and profile of GR promoter $\mathrm{CpG}$ methylation in the hippocampus of newborn piglets. Animal 8: 1851-1856. [Medline] [CrossRef]

32. Tessel, M. A., Benham, A. L., Krett, N. L., Rosen, S. T. and Gunaratne, P. H. 2011. Role for microRNAs in regulating glucocorticoid response and resistance in multiple myeloma. Horm Cancer 2: 182-189. [Medline] [CrossRef]

33. Turner, J. D., Alt, S. R., Cao, L., Vernocchi, S., Trifonova, S., Battello, N. and Muller, C. P. 2010. Transcriptional control of the glucocorticoid receptor: $\mathrm{CpG}$ islands, epigenetics and more. Biochem. Pharmacol. 80: 1860-1868. [Medline] [CrossRef]

34. Turner, J. D. and Muller, C. P. 2005. Structure of the glucocorticoid receptor $(\mathrm{NR} 3 \mathrm{C} 1)$ gene $5^{\prime}$ untranslated region: identification, and tissue distribution of multiple new human exon $1 . J$. Mol. Endocrinol. 35: 283-292. [Medline] [CrossRef]

35. Uchida, S., Nishida, A., Hara, K., Kamemoto, T., Suetsugi, M., Fujimoto, M., Watanuki, T., Wakabayashi, Y., Otsuki, K., McEwen, B. S. and Watanabe, Y. 2008. Characterization of the vulnerability to repeated stress in Fischer 344 rats: possible involvement of microRNA-mediated down-regulation of the glucocorticoid receptor. Eur. J. Neurosci. 27: 2250-2261. [Medline] [CrossRef]

36. Weaver, I. C., Cervoni, N., Champagne, F. A., D’Alessio, A. C., Sharma, S., Seckl, J. R., Dymov, S., Szyf, M. and Meaney, M. J. 2004. Epigenetic programming by maternal behavior. Nat. Neurosci. 7: 847-854. [Medline] [CrossRef]

37. Weaver, I. C., Champagne, F. A., Brown, S. E., Dymov, S., Sharma, S., Meaney, M. J. and Szyf, M. 2005. Reversal of maternal programming of stress responses in adult offspring through methyl supplementation: altering epigenetic marking later in life. J. Neurosci. 25: 11045-11054. [Medline] [CrossRef]

38. Zeisel, S. H. 2008. Genetic polymorphisms in methyl-group metabolism and epigenetics: lessons from humans and mouse models. Brain Res. 1237: 5-11. [Medline] [CrossRef]

39. Zhang, T. Y., Labonté, B., Wen, X. L., Turecki, G. and Meaney, M. J. 2013. Epigenetic mechanisms for the early environmental regulation of hippocampal glucocorticoid receptor gene expression in rodents and humans. Neuropsychopharmacology 38: 111-123. [Medline] [CrossRef]

40. Zhang, W., Zhang, J., Hoadley, K., Kushwaha, D., Ramakrishnan, V., Li, S., Kang, C., You, Y., Jiang, C., Song, S. W., Jiang, T. and Chen, C. C. 2012. miR-181d: a predictive glioblastoma biomarker that downregulates MGMT expression. Neuro-oncol. 14: 712-719. [Medline] [CrossRef]

41. Zou, H., Li, R., Jia, Y., Yang, X., Ni, Y., Cong, R., Soloway, P. D. and Zhao, R. 2012. Breed-dependent transcriptional regulation of 5 '-untranslated GR (NR3C1) exon 1 mRNA variants in the liver of newborn piglets. PLoS ONE 7: e40432. [Medline] [CrossRef] 